\title{
The Political Economy of the Kyoto Protocol
}

\author{
Aynsley Kellow
}

$\mathrm{M}$ UCH writing on the international politics of the environment might suggest that the threat of climate change makes a consideration of national interests somewhat redundant, since, in the face of a common threat, global interests override the interests of states.

Such a belief may be at least partly responsible for the widespread disappointment with the results of environmental policy-making at the international level which was so much in evidence at the 1997 United Nations General Assembly Special Session convened to review progress on the agenda adopted at Rio de Janeiro in 1992 (Sandbrook, 1997). The challenge is no longer to conclude multilateral environmental agreements (MEAs), but to conclude MEAs that are going to deliver positive environmental outcomes. Too often, MEAs have been developed in considerable ignorance of important national interests by delegations to international negotiating meetings at which environment agencies and interests are represented but those of industry and trade are not. It is not surprising that commitments are not honoured in ratification and implementation, and are undermined by domestic policy processes in which interests less influential at the international level are able to extract redress at the expense of reducing MEAs to mere symbolic gestures (Kellow, 1997). While excluded or marginalised in the processes by which MEAs are developed, business is more influential at the level of domestic politics, enjoying what Lindblom (1977:170-88) saw as the 'privileged position of business' thanks largely to its role in delivering investment.

International environmental policy requires states to assume responsibilities, and to undertake actions to give effect to those policies. Unlike domestic policy, new requirements cannot generally be imposed upon agents contributing to the causes of problems. For example, experience with the 1987 Protocol limiting the emission of ozone-depleting substances has shown that some nations are either unwilling or unable to deliver on international commitments, and a thriving black market has undermined the Protocol's effectiveness. Policy adopted in ignorance of significant national interests and important sectoral interests is thus almost certainly doomed to failure, and policy to deal with the risk of a rate of climate change which will tax the adaptive capacities of human and natural systems is no exception.

Aynsley Kellow is Professor of Social Sciences in the Australian School of Environmental Studies, Griffith University. 
It is therefore important to examine the interests involved in the development of the Kyoto Protocol.

\section{Risk, Science and National Circumstances}

In a political sense, the most significant winners and losers in relation to climate change policy are perhaps those affected by the policy rather than by the risk of accelerated climate change. The costs of climate change will be remote in time and interests affected by them poorly organised, but the winners and losers associated with the policies adopted are in the present and much better organised. But it is important to bear in mind that the assessment of the risk posed by accelerated climate change depends crucially upon the circumstances of national and sectoral actors. One's risk assessment differs substantially depending on whether one lives in a low-lying island state, or a state with substantial low-lying land such as Bangladesh or the Netherlands, or an elevated inland state (Adams, 1995). Risk assessment cannot be based upon science alone. It inevitably reflects differing national circumstances and subjective factors. Indeed, one of the problems with the Intergovernmental Panel on Climate Change (IPCC) process is that it seeks in many ways to make a risk assessment which the scientists involved are not qualified to make, and which should be left to the policy-makers. For example, the controversy over the attribution of past observed climatic change to human agency in the Second Assessment Report of the IPCC (Houghton et al., 1996) reflects tensions between the need to produce a scientific consensus and the national and sectoral interests of some participants: the US State Department played a role in revisions to downplay the uncertainty in the science, while fossil fuel interests raised these revisions as a political issue.

The view that a consensus must be produced, rather than allowed to emerge from traditional scientific controversy (as was the case with chloroflurocarbons), presupposes that action will not be taken unless a consensus is manufactured, and thus presupposes that action is needed. Since climate science is based on models of the global climate system which are limited by the computational power of supercomputers, and so is unlikely to resolve the attribution controversy definitively, a risk assessment performed by the IPCC is likely to continue to be contested by those with different interests in the causes, effects, and solutions (see Kerr, 1997). But this is not only unavoidable: it is desirable. The key policy questions are about what costs we should accept to attempt to mitigate how much climate change, and on the basis of what degree of scientific certainty. Not only is science alone unable to provide the answer; neither can the precautionary principle (which states that lack of full scientific certainty should not be a reason for inaction), since it cannot tell us how much precaution we should exercise. Such questions are inescapably political, and inextricably bound up with questions of ethics and interests.

To assume that interests do not matter, and that the imperative of the IPCC scientific consensus and a common threat of climate change will produce an effective and workable international instrument to it, is to risk the whole ability of the international system to respond to the problem. Diverging risk assessments are 
then likely to take over, at the cost not only of the loss of effective response to the risk of climate change, but an even further loss of faith in international processes and institutions. But since there are problems for which effective international capacity is needed, we need to develop a policy response which takes account of the political economy of the Framework Convention on Climate Change (FCCC) and the Kyoto Protocol adopted at the Third Conference of the Parties in December 1997.

\section{Interests and Morality in Climate Change Policy}

A basic difficulty in identifying the interests at stake in the FCCC is that they are confused by a moral cloak of equality which, paradoxically, is grossly unequal. One of the fundamental flaws with the FCCC, with which Australia took issue, is the egalitarian appeal which made agreement in Rio de Janeiro possible: the nonbinding commitment of stabilisation of emissions at 1990 levels for Annex I nations (essentially the OECD countries plus Eastern Europe and the former Soviet Union) by 2000 . Both the egalitarianism of that commitment (and of later calls for uniform reductions in emissions from the European Union (EU) and Alliance of Small Island States for Kyoto) and the use of 1990 as a base year were so unjust as to jeopardise any delivery on commitments.

It was Anatole France (1894) who wrote of the 'majestic equality of the law, which forbids the rich as well as the poor to sleep under bridges, to beg in the streets, and to steal bread'. The circumstances of nations differ hugely: levels of wealth, rates of population growth, rates of economic growth, energy-intensiveness of their economies, requirements for transport, heating and cooling, and energy sources available as the result of natural-resource endowments and past investment decisions. Any requirement which ignores these differences in the interest of a quick consensus-generating appeal to equality is doomed to fail.

The examples of the United Kingdom and Germany, which formed the selfinterested basis of the EU position, reveal the injustice that can be masked by seemingly equal commitments. The privatisation of the UK electricity sector in 1990 and the subsequent demise of the coal mining industry resulted in a 'dash for gas' which made any reductions in $\mathrm{CO}_{2}$ emissions much less difficult for the UK, since gas produces fewer emissions per unit of electricity generated; moreover, new combined-cycle generation lifts conversion efficiencies from the order of 4.0 per cent to around 50 per cent, reducing $\mathrm{CO}_{2}$ emissions by 60 per cent compared with coal. The dash for gas was made possible also by the relaxation in 1990 of a 1974 EU Directive prohibiting the use of gas (as a premium fuel) for electricity generation, and by the need for the UK to limit sulphur dioxide emissions. (A similar 'premium fuel' policy in Victoria can be seen to have resulted in Statecommissioned $3000 \mathrm{MW}$ of brown coal plant over the past decade which was only 25 per cent thermally efficient, thus producing more $\mathrm{CO}_{2}$ per unit of electricity.) UK gas plant capacity and generation now account for about 20 per cent of all fossil fuel capacity and generation (Bantock \& Longhurst, 1995), resulting in a windfall 
emissions reduction, unrelated to climate change policies, of about 12 per cent in the electricity sector since 1990.

Germany was particularly advantaged by both the uniform targets approach and by the selection of 1990 as the base year. German reunification occurred in October 1990; over the following year, economic activity in the former East Germany contracted by 23 per cent and total primary energy consumption declined by around 30 per cent (Boehmer-Christiansen et al., 1993). Ironically, some European nations such as the Netherlands and Denmark were disadvantaged by the selection of 1990 as a base year, because climatic conditions that year gave them an abnormally low level of energy use and thus greenhouse gas emissions as a target.

The 'European bubble' proposal involved setting a single reduction target for the EU, while allowing different targets for each member nation. It thus allowed the serendipitous gains of Germany and the UK to be offset against the excesses of Greece and Portugal, which were to be permitted to increase their emissions by around 30 per cent and 40 per cent respectively. Luxembourg was to have reduced its emissions by 30 per cent, but it can import energy - as can much of Western Europe (Sweden is laying an undersea cable to Poland, for example). But the issue raised by the European embrace of differentiated responses is not only that it was unjust that the EU alone should differentiate, but that, if political agreement within an organisation such as the EU, with its single market and a planned single currency, required recognition to be given to the different national circumstances of its member states, what real prospect was there of worthwhile multilateral agreement being secured without differentiation?

Agreement among Annex I Parties in Kyoto was secured only after acceptance of the need for differentiation by Japan and (eventually) the US. Russia offered to trade its windfall emission reductions, and the US negotiators fashioned a bloc based around Annex I members of the Asia-Pacific Economic Cooperation (APEC) group, which Russia had joined only the previous week, crafting an 'umbrella' of differentiated responses to counter the EU bubble. The negotiation took on all the appearances of a trade negotiation and only an outcome which took account of differing national interests was possible. The agreement included differentiated responses from Annex I Parties, with the net effect that their aggregate emissions of the six most important greenhouse gases would be reduced by at least 5 per cent below 1990 levels in the budget period of 2008-2012. The EU was required to reduce emissions by 8 per cent below 1990 levels, the US by 7 per cent, and Japan by 6 per cent; while, in addition to increases by individual nations within the EU (Greece, Portugal, Spain, Ireland, Sweden), increases were allowed to Australia ( 8 per cent), Iceland (10 per cent) and Norway ( 1 per cent). The agreement also provided for emissions trading, details of which were to be determined at the Fourth Conference of the Parties in Buenos Aires in November 1998.

The Kyoto outcomes are relatively modest, but they are steps towards the development of workable policy instruments that have some prospect of being ratified and honoured (although it must be acknowledged that US ratification is problematic, and Annex 1 Parties will be looking to Washington before they act). Kyoto 
represents the failure of the 'blame and shame' tactics adopted by non-government organisations (NGOs), which sought to promote the moral case for protection from climate change and supported the European position for uniform cuts. Uniform emission targets were not only politically infeasible, but, because of different abatement costs in different countries, inefficient in economic terms and thus wasteful of resources (unless factors such as energy taxes were to be harmonised first). Many commentators have viewed the Montreal Protocol, with its precedent of international agreement in the face of a scientific consensus, as the model for FCCC; but whereas the ozone issue affected a few chemicals of marginal importance, for which some industrial interests made substitutes, climate change entails activities which are of central importance to the national interests of industrialised states. Climate science is also much more complex and much more uncertain, especially with regard to the effects of climate change. The negotiation of the Protocol showed clearly that differences in interests between parties must be recognised and negotiated, and that attempts to submerge them in moral injunctions would not suffice (Sprinz \& Vaahtoranta, 1994; Kellow, 1997).

\section{Trading Emission Rights vs Carbon Taxes}

Consideration of the political economy of the Kyoto Protocol leads us to consider the kind of policy instruments that might be adopted to mitigate greenhouse-gas emissions internationally.

Uniform percentage reductions using regulatory approaches are clearly inferior, especially since they are capable of producing counterproductive effects by creating perverse incentives (Maloney \& Brady, 1988). A policy of percentage reductions of sulphur dioxide emissions in the US favoured the use of high sulphur coal, and was claimed to have produced worse outcomes than would have occurred in the absence of any policy. Kyoto reflects an awareness of this, especially since the absence of commitments by developing countries is likely to have simply resulted in carbon leakage. But such approaches sit well with the 'blame and shame' approach of the NGOs, which locks the problem into the North-South debate. Economic incentives, while usually more effective instruments, are not universally preferred. For reasons explained below, an emissions trading regime, as provided for in the Kyoto Protocol, is to be preferred to the main alternative of an international emissions tax; but the continuing opposition to either mechanism, largely reflecting an ethical objection to any permissive approach to the 'sin' of pollution, could result in difficulties being created in negotiations leading to the development of an emissions trading regime (see Goodin, 1992). The NGOs could well work to sabotage the highly complex negotiations which must now occur, by attempting to burden the regime with unworkable or unreasonable requirements. Care will be needed to avoid this.

Why is emissions trading to be preferred to taxes? A uniform carbon tax applied in all countries would achieve welfare-efficient abatement if the tax were set at the marginal damage costs of $\mathrm{CO}_{2}$ emissions. But the exact nature and value of the physical damage remain unknown. Besides, if such taxes were to be collected domestically, they would create a compliance problem, since they could be partially 
offset by governments reducing existing energy taxes, thus undermining the effectiveness of the international tax. If carbon taxes were to be collected internationally, this would imply a loss of sovereignty which would go beyond the level entailed in the FCCC. There is no precedent for a supranational agency collecting taxes. An additional problem is that international taxes, when combined with the doublestandards provision of the FCCC exempting developing countries from binding commitments, could encourage carbon leakage, since taxes would suppress demand in Annex I nations, thus resulting in lower world prices for fossil fuels and encouraging increased consumption in non-Annex I nations.

Tradeable permits are regarded as preferable to taxes when the costs of abatement are known with greater certainty than the costs of potential damages and there is a significant probability of catastrophic damage (Pearce \& Turner, 1990). These conditions certainly obtain with greenhouse-gas emissions. Once emission permits have been distributed, their value can reflect both developing views of the seriousness of the problem and the cost at which abatement can be achieved, and the market can reflect both changes in scientific knowledge and technological advances without governments having to readjust the level of taxes. If there are significant advances in photovoltaics, nuclear fusion, or $\mathrm{CO}_{2}$ removal from power station emissions, permits will have a lesser value and this will be reflected in the cost of electricity from fossil fuels.

Taxes have the advantage of providing (at least potentially) less uncertainty over price, but at the cost of greater uncertainty over the quantity of emissions. They have some appeal to economists, but they are less likely to be favoured in decision processes driven by science and inevitably centred on atmospheric concentrations and thus quantitative emission limitations and reductions - as the Kyoto process was. Moreover, uncertainties over price under a trading regime can be addressed by futures trading.

The creation of a market in permits, including a futures market to guide longerterm infrastructure decisions, has considerable appeal to economists. Such a market 'should automatically clear at the global marginal cost of $\mathrm{CO}_{2}$ control, thus eliminating the centrally determined estimates of such costs needed to impose an international tax' (Mabey et al., 1997:31). The use of such market instruments is preferred by economists as an alternative to heavy-handed 'regulation', but it should be remembered that they must themselves be underpinned by regulation. This is most obvious in the case of compliance issues in a market for permits, since some form of penalty must be set if nations emit more carbon than is covered by their permits. Since such penalties would have to be imposed by some international body, emissions trading raises sovereignty issues, just as taxes would.

Permit trading between nations would also give them flexibility in their own use of policy instruments to meet their targets: taxes, regulation, subsidies or domestic trading schemes. Such flexibility extends, of course, to the international level. Nations could chose whether or not to trade once the distribution of entitlements were decided, and could make their own decisions based on their assessment of abatement costs and other national circumstances. 
The Kyoto Protocol allows international trading between firms; and while it does not make the establishment of a domestic emissions trading regime compulsory, it is highly likely that nations will decide to establish such systems as a means of integrating domestic climate change policy with the international system. The full ramifications of such developments will become evident only with time. Divisions will emerge between industrial sectors, most obviously between 'sink' sectors (such as forestry) and emitting sectors. It will take a considerable time for all these sectors to understand how their interests are affected. The proposal by McKibbin and Wilcoxen (1997) for national based emissions trading only in the absence of targets would have been much less problematic, but that is now not likely to be adopted unless Kyoto fails - as is possible.

There would appear to be insufficient time between now and the Fourth Conference of the Parties in November 1998 for the details of an international emission trading regime to be defined and designed, let alone negotiated. A likely outcome is a 'Buenos Aires Mandate', followed by another series of meetings of an ad hoc group to progress it. Yet international climate change policy appears headed in the right direction.

If entitlements are distributed initially much in line with existing uses, and reflect national determinations of abatement costs, their impact need not be too severe and industry will not oppose them as vigorously as they would taxes. Questions arise over such issues as entitlements for new industries, but there is no reason why they cannot be purchased from sink industries such as forestry or from those making energy-efficiency gains or other means of abatement. This is likely to affect the competitiveness of location in Australia only marginally for most industries, since energy costs are only one of several locational factors. Given that brownfields expansion in sectors such as aluminium smelting is likely to be cheaper than greenfields expansion elsewhere, and given that Australia still has substantial reserves of cheap coal, assigning property rights to carbon emission entitlements will not have the same impact on Australia's future economic prospects that a percentage reduction with no trading would have - while still creating incentives for emission reductions and sink creations.

An emissions trading regime could be responsive to the emerging science over both the extent of climate change and the distribution of its costs and benefits, whereas this would not be possible with carbon taxes, since one needs a good idea of the amount of the damage in order to set the rate of tax. While the rate of tax could be adjusted in the light of climate science, a tax could not be guaranteed to deliver the specified quantified reductions favoured by international negotiations.

An issue that has to be resolved is the incorporation of reductions in land clearing in Australia's allocation of permits, and how the gains resulting from reductions in clearing rates since 1990 should be distributed. A further issue is who should benefit from sink creation paid for under the Natural Heritage Trust Fund. These issues imply a need (presumably) to enforce covenants over land-based sinks to ensure that subsequent landholders continue to manage them in such a way that they continue to lock up carbon. The superiority of emissions trading makes it 
worthwhile to resolve these problems, even though they are not likely to be resolved in time for the meeting in Buenos Aires.

\section{Environmental Technology and Unintended Consequences}

A note of caution should be sounded about the possible unintended environmental effects of emissions trading. Enthusiasts for different energy sources, whether inspired by technical or economic considerations, are prone to understate the associated drawbacks. In the early 1980s, the Tasmanian Hydro-electric Commission often claimed that (land use and wilderness values aside) hydro-electricity was nonpolluting. This claim overlooked the temperature pollution which can kill wildlife when water is released from deep storages, the supersaturation with nitrogen which can result from releases from high spillways, and the heavy metals which can be mobilised from vegetation and geological formations. As well, the methane released from the creation of a hydro storage in some locations could have roughly the same effect on climate change as would the generation of an equivalent amount of energy by the burning of fossil fuels.

This principle extends to many of the technologies that are advocated so enthusiastically as being 'renewable'. The largest wind farm in the world, at Altamont in California, has a visual impact, makes noise, causes soil erosion and kills more birds every year than were killed by the Exxon Valdez, the oil tanker that foundered on the Alaskan coast in 1989. Solar thermal and photovoltaic arrays have similar impacts, and photovoltaic cell production gives rise to emissions of toxic arsenic, gallium and cadmium. The land requirements for central photovoltaic arrays are 24ha/MW of installed capacity, and solar thermal slightly more. A $2000 \mathrm{MW}$ power station would thus require in the order of 5000ha of land, which would have to be purchased and would amount to a substantial 'footprint' in an important habitat. Such technologies should not necessarily be eschewed - many of the impacts noted above can be minimised with careful siting, for example — but their costs as well as their benefits should be calculated. In view of this, attempts at 'green energy' labelling which include the renewables listed above but exclude coal-bed methane (see, for example, SEDA, 1997) are open to question. Given that coal is likely to be extracted to some extent in Australia for a very long time, it makes sense to use a significant greenhouse gas to produce energy rather than to release it into the atmosphere.

\section{Conclusion}

The Kyoto Protocol has not been widely welcomed. Environmentalists in Australia tend to see it as letting Australia off lightly, while greenhouse sceptics reject it as imposing legally binding requirements to reduce emissions they see as unwarranted.

\footnotetext{
' See Bradley (1997). It should be noted that Bradley is an enthusiast for gas, but this underscores the need for the different interests on issues such as climate change to probe the weaknesses of different schools.
} 
Especially because it does not include any binding commitments from developing countries (not even to slow growth in emissions), its ratification by the US Senate is highly problematic.

Realistically, Kyoto must be seen as the first step in a long process to create a set of 'insurance institutions'. Much detail in terms of compliance mechanisms and provisions for emissions trading is yet to be defined, and this is not likely to be completed at the next Conference of the Parties. But while Kyoto was but a first step, it inaugurated a journey in a promising direction. While some might argue for the superiority of taxes, the provision for emissions trading adopted in Kyoto appears better suited to both the problem in hand and the realities of international negotiation, although both raise important issues such as sovereignty.

The acceptance of differentiation was inevitable since Parties would commit only to what they considered equitable in the context of the circumstances of others. In the face of the European bubble, no responsible government is likely to have committed to a binding target which implied a greater burden for its citizens than was being accepted by the Europeans. If the special circumstances of Spain, Greece, and Sweden were accepted within the EU as grounds for allowing differentiated commitments, then why should those of Iceland, Norway and Australia be ignored? And if Germany and the UK could trade their windfall reductions within the EU, why not Russia within APEC? Not only was differentiation fair, it was realistically the only possible outcome

Kyoto represents the triumph of interests over idealism in international negotiations. It is a modest success which remains vulnerable to both interests and ideals.

\section{References}

Adams, J. (1995), Risk, , UCL Press, London.

Bantock, J. \& J. Longhurst (1995), 'UK Electricity Requirements and the Environmental and Economic Aspects of the Development of the Combined Cycle Power Station', The Environmentalist 15: $122-38$.

Boehmer-Christiansen, S., D. Merten, J. Meissner \& D. Ufer (1993), 'Fcological Restructuring or Environment Friendly Deindustrialisation: The Fate of the East German Energy Sector and Society since 1990', Energy Policy 21: 355-73.

Bradley, R. (1997), Renewable Enengy: Not Cheap, Not 'Green', Cato Institute, Washington DC (Cato Policy Analysis No. 280).

France, A. (1894), Le Lys Rouge, Ch 7, cited in the Oxford Dictionary of Quotations, 4th. ed., Oxford University Press, Oxford.

Goodin, R. (1992), 'Green Values and the Buying of Environmental Indulgences', paper presented to the conference 'Working Our Land to Death? Knowledge, Values and Action', University of Melbourne (July). 
Houghton, J., I. Meira Filho, B. Callander, N. Harris, A. Kattenberg \& K. Maskell (eds) (1996), Climate Change 1995: The Science of Climate Change, Cambridge University Press for the IPCC, Cambridge.

Kellow, A. (1997), 'Problems in International Environmental Governance', Australian Journal of Public Administration 56: 54-64.

Kerr, R. (1997), 'Greenhouse Forecasting Still Cloudy', Science 276: 1040-2.

Lindblom, C. (1977), Politics and Markets, Basic Books, New York.

Mabey, N., S. Hall, C. Smith \& S. Gupta (1997), Angument in the Greenhouse, Routledge, London.

McKibbin, W. \& P. Wilcoxen (1997), A Better Way to Slow Global Climate Change, Brookings Institution, Washington DC (Brookings Policy Brief No. 17).

Maloney, M. \& G. Brady (1988), 'Capital Turnover and Marketable Pollution Permits', Journal of Law and Economics 31: 203-26.

Pearce, D. \& K. Turner (1990), Economics of Natural Resources and the Environment, Harvester Wheatsheaf, London.

Sandbrook, R. (1997), 'UNGASS Has Run Out of Steam', International Affairs 73: 641-54.

Sprinz, D. \& T. Vaahtoranta (1994), 'The Interest-based Explanation of International Environmental Policy', International Organization 48: 77-105.

Sustainable Energy Development Authority (SEDA) (1997), Green Power Accreditation Program: Accreditation Document (Version 1.1, September), Sydney. 